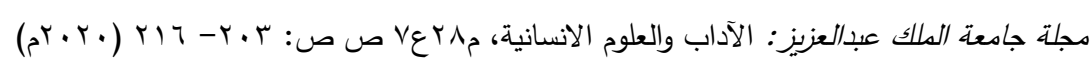

$$
\begin{aligned}
& \text { DOI:10.4197/Art.28-7.9 }
\end{aligned}
$$

\title{
مفهوم الإعلام الهادف وواقعه في القنوات الفضائية
}

\author{
د. دائشة بنت محمد بن سعد القرني \\ أستاذ مساعد في العقيذة والدعوة - قسم الثريعة والدراسات الإسلامية \\ بكلية الآداب والعلوم الإنسانية بجامعة الملك عبد العزيز بجدة
}

مستخلص. هـذا البحث بعنوان: (مفهوم الإعـلام الهـادف وواقعـه في القنـوات الفضــائية) تــاول بالدراسـة الدور الإعلامسي والآثار الدعويـة المعاصرة للقنوات الفضـائية، وذلك من خـلال توضيح أهميـة القنوات الفضـائية بالنسبة

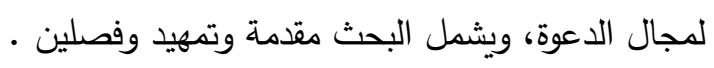

الرسالة، التي ترغب التربية الإسلامية في إيصالها

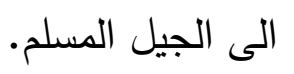

\section{مشكلة البحث}

إن الآثار الإيجابية والسلبية للبث المباشر لها الأثر

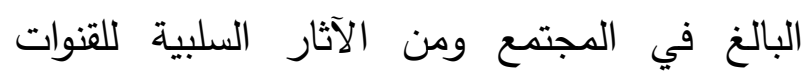
الفضائية عدم الموازنة بين البرامج الإعلامية من الناتئ

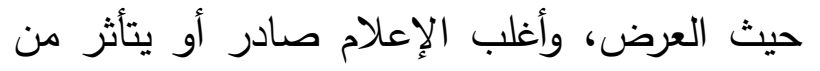
دول غير إسلامية ويُستقبل داخل البلدان الإسلامية.

(1) (1) (1) (1) : (1).

\section{المقدمة}

إن الإسلام يشكل نظاماً متماسكاً، وله نظامه الأخلاقي الخاص وعقيدته الخاصة.

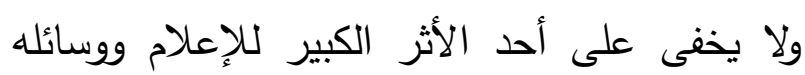

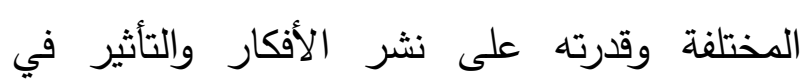
المفاهيم وحتى في الأسس الأخلاقية والتربوية.

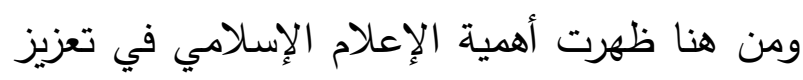
المفاهيم الإسلامية، والأخلاق الحميدة.

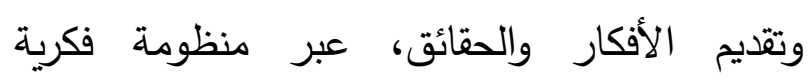
ودلالية، باستخدام الدفاهيم والمبادئ المكونة لجوهر 
جاء الدافع الاختياري لهذا الموضوع الهام.

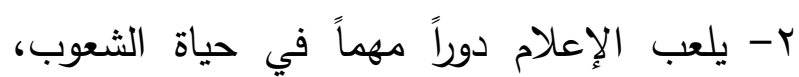
فيظل الإعلام المعاصر بتقنياته المتطورة ووسائله المختلفة رمزاً من رموز التحضر ، ومعلماً من معالم التقدم بين الأمح. ب- يعتبـر التليفزيـون إحدى أهم وسـائل الاتصـال

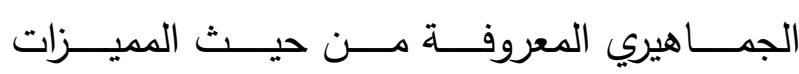

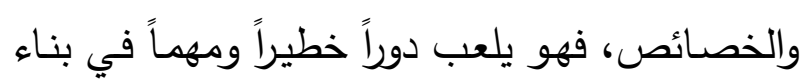
المجتمعات الإنسانية والحضارية سلباً وإيجاباً. الاراسات السابقة: 1- دراسة بعنوان: (دور الإعلام الديني في تغيير

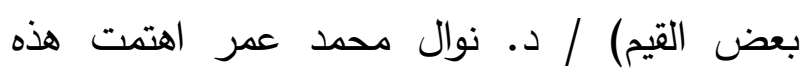
الدراسة بوسائل الإعلام في العصر الحديث وصلت مصلتها بالإعلام الديني بشكل مفصل وشامل لأدواره أما هذا البحث فيتناول القنوات الفضائية . فروض الدراسة: تتمثل فروض الدراسة في الإجابة عن الأسئلة

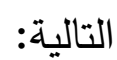

1- ماهو مفهوم الإعلام في اللغة والاصطلاح؟ r- ما هي خصائص التلفزيون الدولي؟ ب- ما هي الوظائف التي يؤديها التلفزيون الدولي هائي

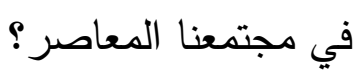
ع- ما هي الآثار الإيجابية والسلبية للقنوات الفضائية؟

0- ما هو الإعلام الدعوي الهادف؟ צ- ما هي القواعد المنهجية للقنوات الدعوية؟

\section{أهداف البحث}

1- بيان مفهوم الإعلام لغة واصطلاحاً. r- معرفة خصائص ووظائف التلفزيون الدولي وأثره

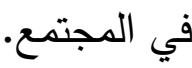
r- عرض الآثار الإيجابية والسلبية للقنوات

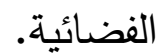
ع- استتباط خطوات العمل الأساسية للإعلام الدعوي الهادف، والقواعد المنهجية للقنوات الفضائية. أهمية الموضوع: إن الحكم على القنوات الفضائية مرتبط بطبيعة الاستخدام، وهذا ما يوضحه هذ البحث.

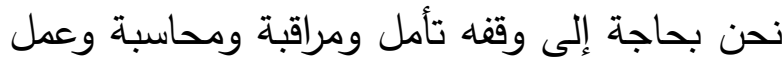

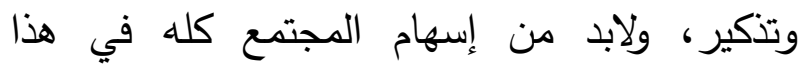
الواجب لاسيما أن حضارتنا حضارة الإسلام إيمانية

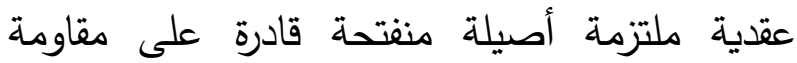
التحديات والصعوبات، متوازنة، شاملة، إيجابية، هادفة تعبر عن طموح الإنسان لإعمار العالم (1).

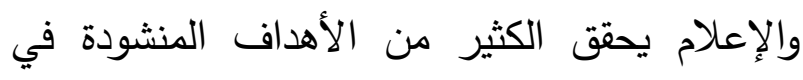

$$
\text { أسباب الاخه الحضارة. }
$$

1- لم يعد الإعلام ظاهرة محدودة في المكان

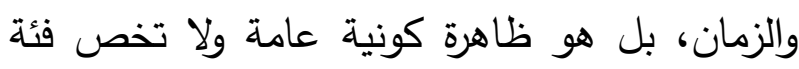
معينة أتيح لها شركات عملاقة وأموال طائلة وجهود

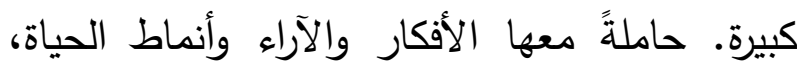
التي تتطلب السعي إلى فهم هذه الظاهرة، واهتلاك

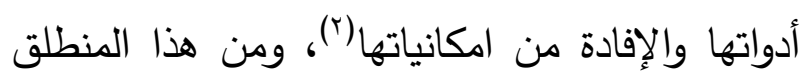

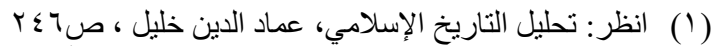

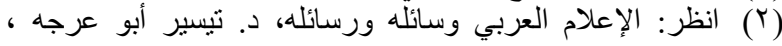


r- تبادل المنافع والمصالح والتعاون قال تعالى :

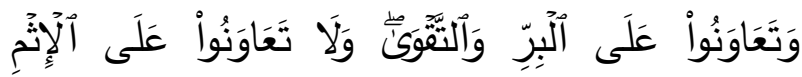

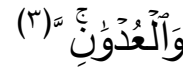

r- اشباع غريزة السيطرة والتملك وهذا يتم بإعلان الشخص عن نفسه لمن يرغب فيه، والأمر الذي يتطلع إليه بكل وسائل التأثير والاستحواذ من خلال الترغيب والترهيب ووسائيل المؤثرات العقلية والنفسية. من رحمة الله بالإنسان أنه سبحانه وتعالى لم يتركه في الأرض تائهاً حيراناً تتغلب عليه شياطين الجن والإنسن وتزين له طريق الغواية والفساد بشتى أله الأساليب بل أرسل الله الرسل وأنزل الكتب وسن الشرائع وفرض الحدود صيانة لعقيدة الإنسان وحفاظاً على فطرته ومن ذلك أساليب الإعلام والدعوة التي تلتزم بالضوابط العقائدية والأخلاقية وتسمو بالإنسانية. ولفت العقول وتوجيه الفكر إلى معرفة صفات الله

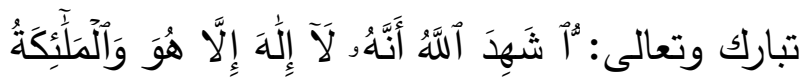

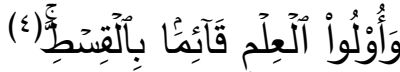

وقد خُتمت الرسالات بدعوة الرسول صلى الله عليه وسلم التي قامت على الدعوة والإعلام الذي اتخذ وسائل وأساليب تقوم على موعظة حسنة ومجادلة

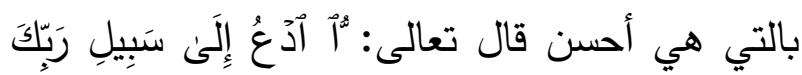

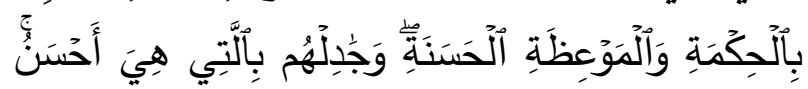

\section{منهج البحث:}

اتبعت في هذا الدراسة المنهج الاستقرائي في عرض ملت المعلومة والمنهج التاريخي في التتبع لها، حيث قمت باستقراء كامل للإعلام ووسائله ووضحت أهم النقاط، أما المنهج الوصفي فاستخدمته لإعطاء صورة حقيقية عن الإعلام وبعض النسب لبعض البرامج في القنوات وعرض آثارها ومن ثم التوصل عن طريق المنهج الاستنباطي إلى أهم الوسائل التي تسعى بالوسائل الإعلامية لتحقيق الهدف المنشود منها.

\section{التمهيد}

الإنسان بفطرته يميل لاستمالة الآخرين والتأثير عليهم والتودد لهم والتعرف عليهم. وهذا هدف أصيل من خلق الإنسان قال تعالى :ُّاّ

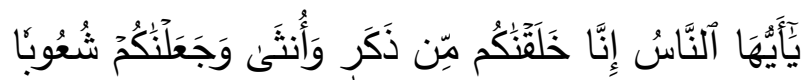

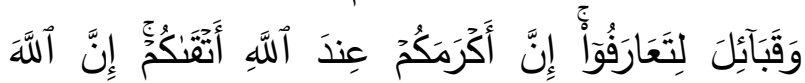

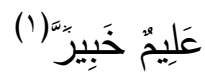
فالهدف الأساسي بعد عبادة الله وتوحيده أن يتعارف الناس وهذا التعارف يتم عن طريق النسب والمصاهرة والرفقة في الحل والترحال قال تعالى: ُّر

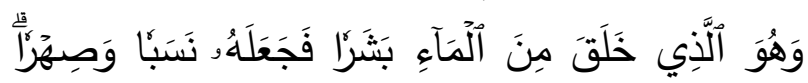

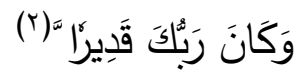
وبسائل التعـارف: ولت وليرف 1- النسب والمصاهرة والصُحبة. 


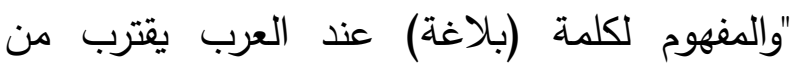
الدفهوم الحديث لعملية الاتصال، فالبلاغة تنبأى عن لئل

$$
\text { الوصول والانتهاء". (v) }
$$

ونجد أن الأنباء بمعنى أخبرك بما لا تعلم، ومنها

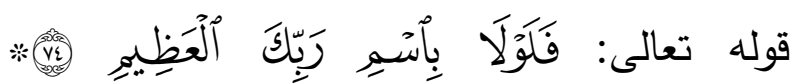

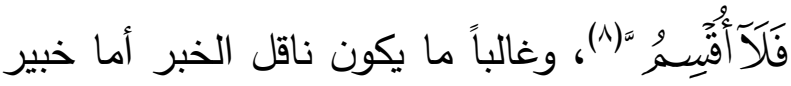
به أو غير خبير به أي مجرد شاهد أو سامع أو أو نائ

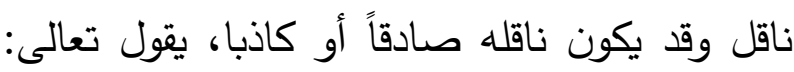

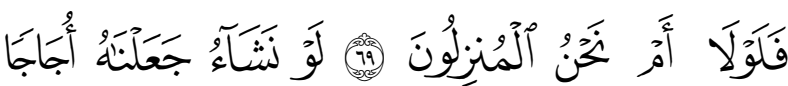

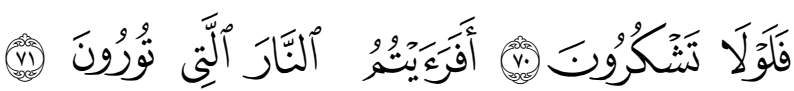

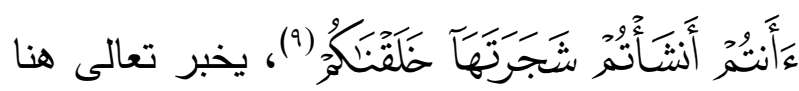
عن حال كثير من أهل الأرض أنهم الضال، وهم

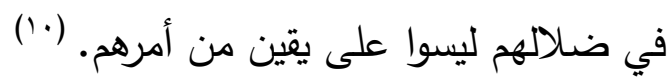
يقال: "بلغ فلان مراده إذا وصل، وبلغين هن هره هو إبلاغاً وبلغه تبليغاً، ومنه قول أبي قيس بن بن الأسلت

قالت ولم تقصد لقيل الخنا مهلاً فقد أبلغت أسماعي". (II)

$$
\text { الإعلام اصطلاحاً: }
$$

تعددت تعريفات الإعلام نحتار منها التعريفات

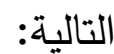

يعرف الإعلام بأنه: نشر وإيصال للحقائق والأخبار

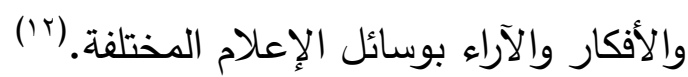

(V) الإعلام الإسلامي بين الأصالة والمعاصرة، محد غياث مكتبي،

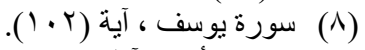

(9) (1) سورة الأنعام، آية (1) (1) (1). (1).

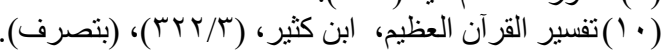

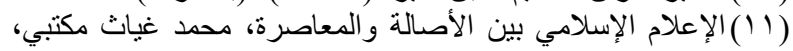

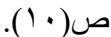

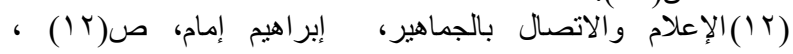

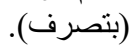

$$
\text { وسائــل الفصل الأول }
$$

• المبحث الأول: مفهوم الإعلام الإعلام

• المبحث الثاني: التلفزيون الدولي وأثرون.

المبحث الثالث: الأقمار الصناعية.

$$
\text { مفهوم الإعـلام الأول }
$$

الإعلام لغة: مصدر الفعل الرباعي أعلم، يقال : أعلم يعلم إعلاما.. وأعلمته بالأمر: أبلغته إياه، الاعلم، لفال وأطلعته عليه، جاء في لغة العرب: (استعلم لي خبر فلان وأعلمنيه حتى أعلمه، واستعلمني الخبر الغربه فأعلمته إياه). (') من مادة علم، والعلم: نقيض الجهل، وعَلٍِ علماً، وعَلمَ هو في نفسه تعليماً. أذن بالشيء إذناً وأذاناً وأَذانة: علم به. هو في (؟)

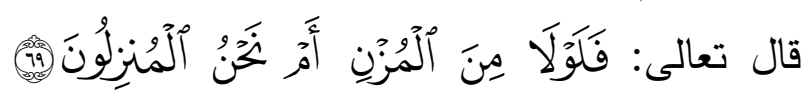

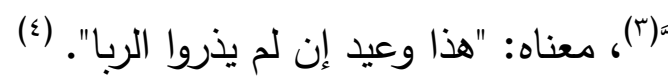
قال الفيروز آبادي: علمه كسمعه علما وعرفه وعلم هو نفساه ورجل عالم وعليك جمعها علماء، وعلام كجهال وعلمه العلم وتعليما وعلاما واعلمه إياه

فتعلمه. (0)

قال صاحب كتاب العروس: الإعلام كلمة مشتقة

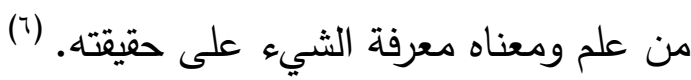

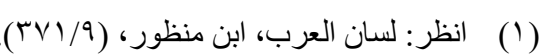

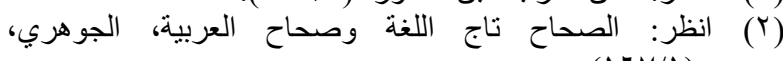

$$
\begin{aligned}
& \text { (17V/1) }
\end{aligned}
$$

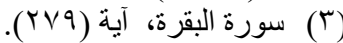

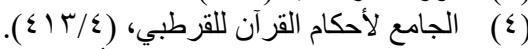

$$
\begin{aligned}
& \text { (0) (نظر: القاموس المحيط، الفيروز أبادي، ص(ك) (100). }
\end{aligned}
$$

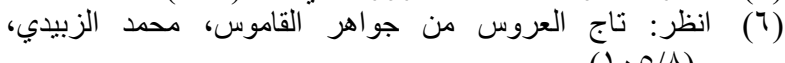


وأيضاً يعرف بأنه: العملية الإعلامية التي تبدأ للناس.

ب- لله القدرة على تركيز اهتمام الناس في أشياء

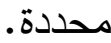

ع- عدساته تكبر صورة الأشياء التي لا تراها

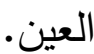

إن مسؤولية التلفزيون كبيرة في رفع مستوى المشاهد صغيراً وكبيراً، ويسهم في بناء الأسس الفكرية والاجتماعية(0)، فالشاشة الصغيرة تتحرك بسرعة إلى لى مختلف قطاعات المجتمع وفئاته. أهم الوظائف التي يؤديها التلفزيون الدولي في

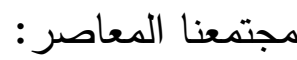
1- الوظيفة الإخبارية : إذ تشكل الأخبار المادة الرئيسة لأغلب المحطات التلفزيونية ووظفت في عملية نقل الأحداث فور وقوعها سواء كانت محلية أو عالمية مباشرة على الهواء أو عن طريق الأقمار الصناعية، وقد عمدت أكثر محطات التلفزيون الغربية في توظيف الأخبار لأغراض سياسية معينة مثل: أ- الأخبار سلعة استهلاكية: وهذا ما يتداوله الإعلام الغربي، سلعة استهلاكية، يجب بيعها وتسويقها إلى الناس، بقصد إرضاء رغبات وميول المتلقين وإثارة انتباههم، رغم أن محتوى الأخبار واحد لكن هناك التفنن في العرض. ب- - الصورة الوهمية الخادعة: هناك أمور سياسية خطيرة تحدث في العالم الذي نعيش فيه ولكن الأخبار تقدم نسخة أخرى من الحدث الفعلي. ج- استخدام الرموز والمصطلحات: غالباً ما تستخدم

(0) انظر : صحيفة عكاظ (محرم 11 (هـ) بمعرفة المخبر الصحافي بمعلومات ذات أهمية الإبلاغ بها. (1) وأيضاً: الإعلام هو التعبير الموضوعي الذي ينقل بوضوح عقلية الجماهير . (r) وكما يعرف بأنه: تزويد الناس بالأخبار الصحيحة والمعلومات السليمة والحقائق الثابتة التي تساعدهم على تكوين رأي صائب في واقعه من الوقائع أو مشكلة من المشكلات أو ظاهرة بحيث يعبر هذا الرأي تعبيراً موضوعياً عن عقلية الجماهير وأفكارهم واتجاهاتهم وميولهم. (r) وهو النقل للمعلومات والمعارف والثقافات الفكرية والسلوكية بطريقة معينة خلال وسائل الإعلام والنشر الظاهرة والمعنوية ذات الشخصية أو الاعتبارية بقصد التأثير وهو التعبير الموضوعي الذي يوضح عقلية الجماهير وميولها واتجاهاتها النفسية في نفس الوقت. (ع)

\section{المبحث الثاني \\ التلفزيون الدولي وأثثر}

أولاً: خصائص التلفزيون:

1- - يعتمد على السمع والبصر في عرضها للحركة مع الصوت لذا يؤثر على الناس وله قدرة على الانتشار وجذب الناس.

r- يختصر الزمان بين حصول الحدث وعرضه

(1) الصحافة اليومية والإعلام، سامي ذبيان، ص(ب) إب) ، (بتصرف).

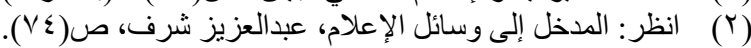
(r) انظر: الإعلام الإسلامي رسالة وهدف، سمير بن جميل راضي،

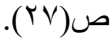
انظر : المرجع السابق، ص (YV) (YV). 
كيت عالم انجليزي مقالاً يقترح فيه وضع جرم صناعي على علو مرتفع في الفضاء، لكي يحل

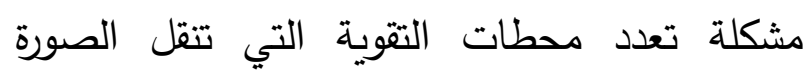
التلفزيونية إلى أماكن بعيدة. وكانت المشكلة قائمة في التلفزيون؛ لأن طبيعة المانة موجاته لا تسمح بالانتقال والوصول إلى أبعد من فئل

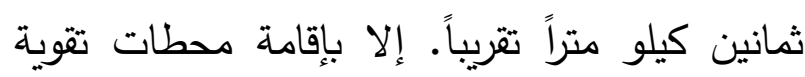

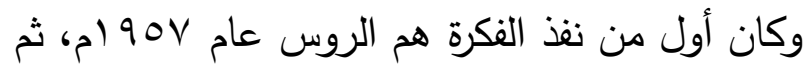
تلتها أمريكا. أطلقت أمريكا أول قمر صناعي لها عام ، .97 (م، وفي عام 970 ام أنشئت منظمة عالمية للأقمار الصناعية (انتلسات) تشترك فيها معظم دول العالم".

إن استعمال الأقمار الصناعية في خدمة البث

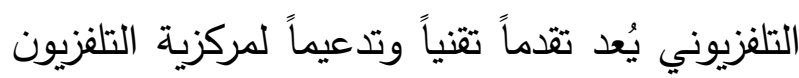

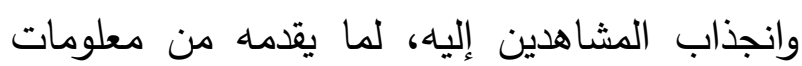
وأحداث فور وقوعها على المستوى الكوني. حيث إنه يتم التقاط البث التلفزيوني في بعض الب البلد البدان وبثه إلى إماكن أخرى تبعد مسافات بعيدة دون أن

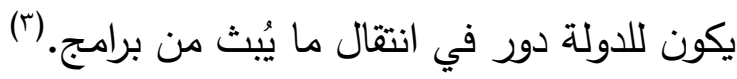

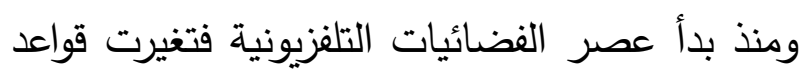
كثيرة في العمل التلفزيوني بعد أن كان التلفزيون

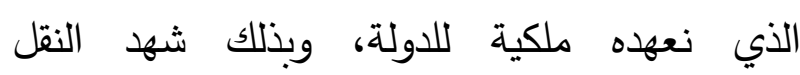

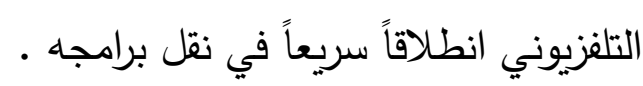
القنوات الفضائية)(؛)

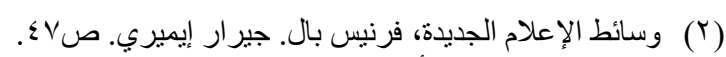

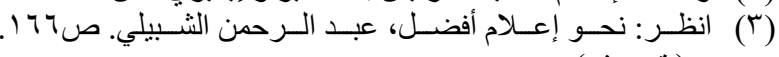

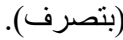

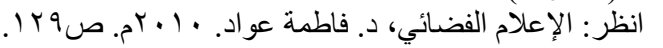

الرموز والمصطلحات لتسويغ أعمال سياسية معينة من قبل السياسيين مثلاً استخدام مصطلح "غارات

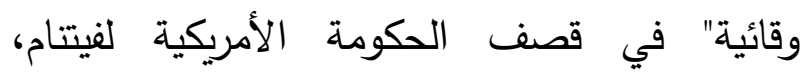
أوالحرب النظيفة في الهجوم الأمريكي الصاروخي

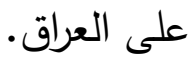
د- الأخبار المصطنعة: هناك نوع من الأخبار تتشر

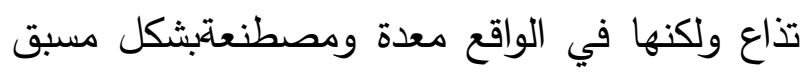
لأغراض سياسية ودعائية.

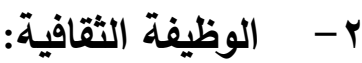

يعتبر التلفزيون من أهم مصادر الثقافة وترويجها إذ يقدم سلع ثقافية عديدة من خلال الاحتكاك بالحضارات العالمية والإطلاع على معالم البلدان وأثارها، إنجازاتها والتزود بمضامين كثيرة من البرامج

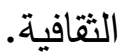
ويساهم التلفزيون بنقل التراث الحضاري من جيل

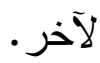

\section{ب- الو الوظيفة التربوية:}

في مجال التربية والتعليم اكتسب التلفزيون فاعليته في الانتشار ؛ لأنه يسمح لمدرس واحد بتوجيه رسالته التعليمية لملايين المشاهدين، وعليه فإن الآثار

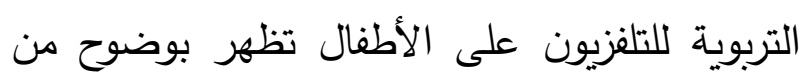

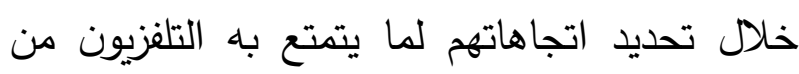
قدرات فائقة في جذب الانتباه وإثارة الاهتمام ('). المبحث الثالث الأثاء الأقمـار الصناعيـة " جاءت فكرة الأقمار الصناعية عام 9 الامعار عند (1) انظر : الإعلام المعاصر وتثقنياته الحديثة ، د. محمد هاثم الهاثمي.

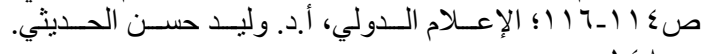
ص ص (1) 
من أحكام كالحجاب وتعدد الزوجات وغيرها، ولعل

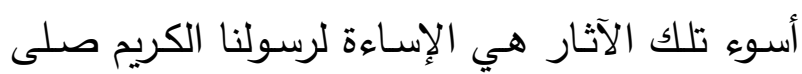

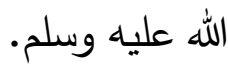
لقد سهح الإعلام الغربي لنفسه بالتطاول على النبي محمد صلى الله عليه وسلم، وتمادى بعداوته بما عبرت عنه الرسوم والفيلم المسيء للإسلام والمسلمين.

إن تكرار الإساءة يعكس صعود فكر عنصري متعصب مسموم في بعض المجتمعات الغربية يظهر من خلاله الصراع بين الأديان والحضارات. لذا وجب على المسلمين أن يردّوا ويحاوروا ويظهروا عظمة الدين ورسالته ويذودوا عن النبي صلى الله عليه وسلم بالطرق المناسبة. فعدم الاستفادة المثلى من القنوات الفضائية قد يترتب

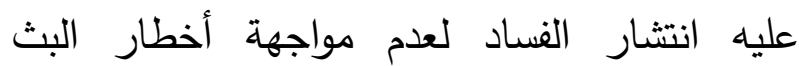
المباشر - المبان وهذا ما حصرت عليه بعض القنوات في القيام بواجبها تجاه دينها وأخلاقها. "ذكرت قناة نورسات الفضائية في احتفالها بمرور

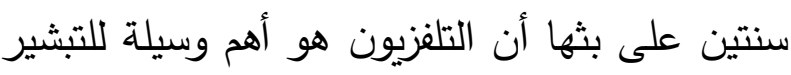
في العصر الحاضر، ولا يُمكن أن تتخلى الكنيسة عن التلفزيون كأداة تبشيرية لبثّ البرامج التتصيرية لئية

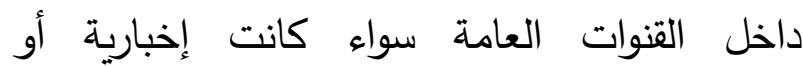

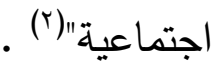

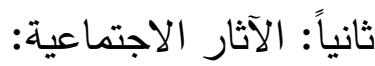
- - إضاعة الوقت وصرف الطلبة عن الدراسة.

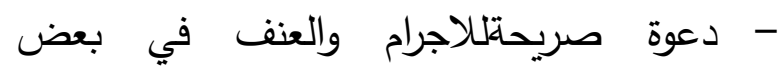

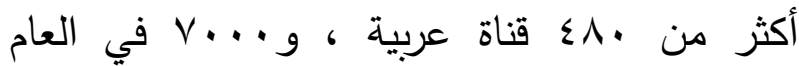

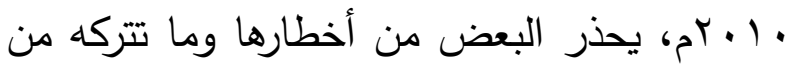
آثار نفسية على أطفالنا وثقافة شبابنا وأفكار مجتمعاتتا والبعض الآخر يهوّن من هذا الخطر

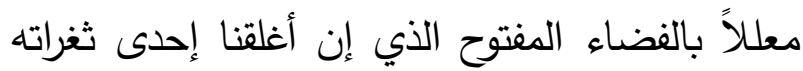

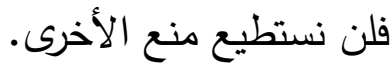
الفصل الثاني الآثار الدعوية م المبحث الأول: آثار القنوات الفضائية.

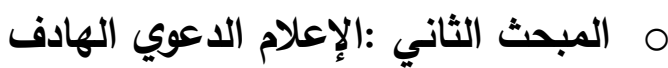
آثار القنوات الفضائية

من سلبيات القنوات الفضائية ومظاهر خطورتها: أولاً: الآثار الدعوية:

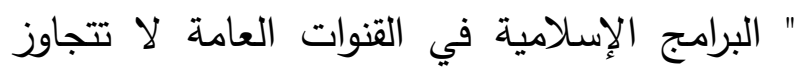

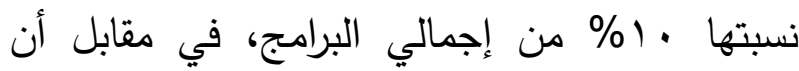
البرامج والقنوات الإسلامية لا تتجاوز نسبتها 0 10 من برامج القنوات العشر الأولى مثل قناة المجد القرآنية في المركز^^1، تلتها قناة بداية في المركز 19، ثم قناة الرسالة في المركز • ب، والإحصائية

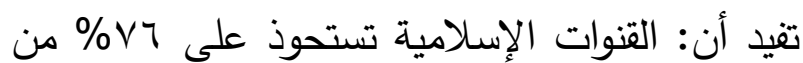

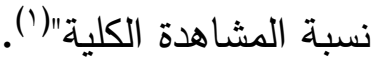
- نشر الدجل والسحر والثرك والإيحاء بقدرة بعض نساء الخلق على مضاهاة الله في الخلق والغيب ووجود بعض الأفلام والبرامج التي تسعى لتشويه الإسلام.

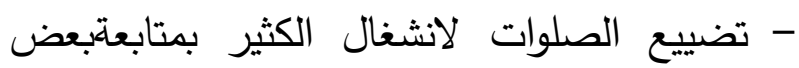
البرامج، وانتقاص أجر الصائمين . - الطعن في بعض ما جاءت به الشريعة الإسـلامية 
المبحث الثاني

الإعلام الاعوي الهادف

بدأت بعض القوات الفضائية تخطو خطوات حثيثة نحو الإعلام الهادف فالتطوير كنافذة على العالم، حينما تبث برامجها للشعوب العالمية وتثير النزعات الفطرية الإنسانية المشتركة وهذا ميدان تتاوله الخطاب القرآني في مخاطبة الناس، ويمكن الانطلاق من الآيات للتواصل على شعوب العالم من خلال إعلامية صادقة تبرز الوجه الحضاري للإسلام وتظهر مظاهر تكريم الله للإنسان قاطبة، قال تعالى:

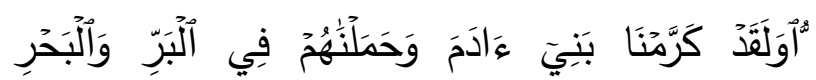

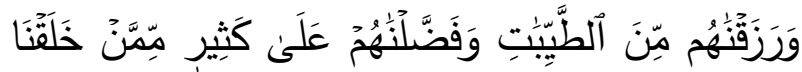

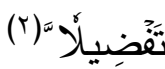
والإعلام الهادف استخدام منهج اسلامي بأسلوب فني إعلامي يقوم به مسلمون عالمون عاملون بدينهر متفهمون لطبيعة الإعلام ووسائله الحديثة وجماهيره المتباينة مستخدمون تلك الوسائل المتطورة لنشر الأفكار المتحضرة والأخبار الحديثة والعقائد الدينية والقيم الأخلاقية والمبادئ والمُثل للمسلمين من كل زمان ومكان في إطار من الموضوعية التامة بهدف التوجيه والتوعية والإرشاد لإحداث التوجيه المطلوب. وتزويد الجماهير بصفة عامة بحقائق الدين الإسلامي المستمدة من كتاب الله وسنة رسول الله صلى الله عليه وسلم بصفة مباشرة أو غير مباشرة من خلال وسيلة إعلامية دينية متخصصة او عامة، رسوله بوساطة قائم بالاتصال لدية خلفية واسعة، ومتبعة في موضوع الرسالة التي يتتاولها، وذلك بغية

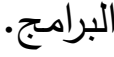

- مبالنسبة للأسرة فكثير من البرامج تدعو لتمرد

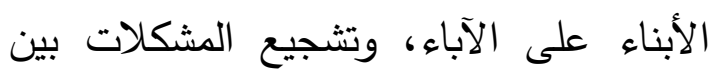

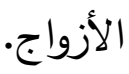

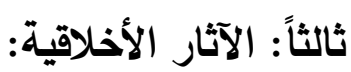
- - إثارة الثهوات مما يسبب كثرة الفواحش. - تعليم المشاهدين الغناء والخلاعة والعلاقات المحرمة وكل ما يجر إلى الرذيلة. - - تصوير بعض الرذائل مثل الرشوة والكذب على الردئ أنها بطولة وذكاء. رابعاً: الآثار النفسية والصحية: بالإضافة للأضرار النفسية الناتجة عن النائه العملية التربوية لهذه القنوات التي تؤدي إلى الصراع النفسي لني بنشر الخوف والعدوان وكثرة السهر والجلوس

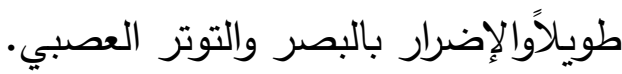

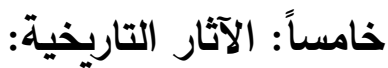
تحريف حقائق التاريخ بإظهار بيئة مُبتذلة لأدوار قادة الفتح الإسلامي والعلماء. مثال: قامت القنوات الفضائية بنقل وبث أخبار القضية الفلسطينية في بدايتها ثم لم تلبث أن تراجعت عن إعطاء هذا الحدث أهميته فبدأت في اقتراف الأخطاء تجاه هذه القضية بتقديم المحاورين العرب العاء

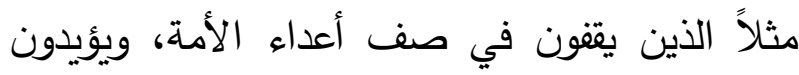
المشروع الصهيوني. وقوع بعض الفضائيات في إثارة النعرات والاختلافات المذهبية بين المتحدثين وما تزال الفضائيات تتابع الانتفاضة بشيء قليل من الاهتمام مصحوباً بصورة خاطئة (') (الانغلة 
على مر العصور . (')

وهكذا يصبح اجتماع هذه المعالم الرئيسية: العصرية، المهنية، الانفتاح الفكري والحضاري هو أكبر نجاح إعلام فضائي هادف، يجمع بين جدية المضمون ومتعة العرض.

ومما حرصت عليه بعض القنوات للدول الإسلاميه

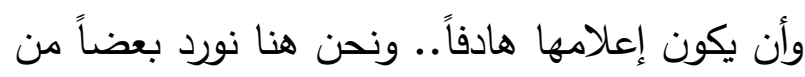

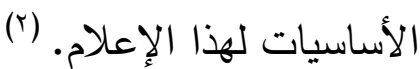
خطوات العمل الأساسية للإعلام الهادف: - تخطيط البرامج لتقديم خدمة متوازنة تجمع بين الإعلام والتثثيف والترفيه في إطار من الإلتزام بمبادئ الدين الإسلامي الحنيف. - - دعوة المسلمين بعضهم بعضاً إلى الخير، قال تعالى: - دعوة غير المسلمين إلى الدخول في الإسلام. - صيانة الحقائق الدينية والمفاهيم الإسلامية من التحريف وإخضاعها للتصورات العصرية الغربية. - الدعوة إلى التعلم.. فالعلم طريق إلى الإيمان. - تأكيد معنى الحرية. فالإسلام أعطى الحرية الكاملة للإنسان.. وهي مقيدة بعدم المساس بمبادئ الإسلام أو الإساءة إليه.

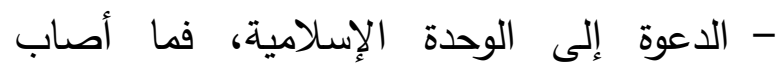
المسلمين وما يصيبهح بسبب كونهم غير متحدين،

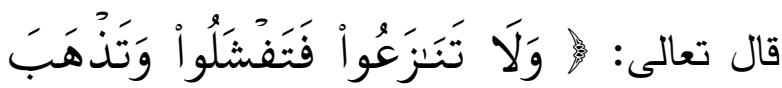

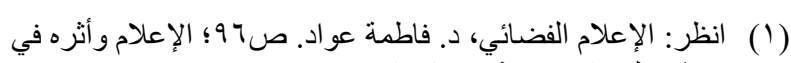

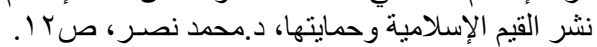

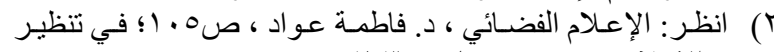

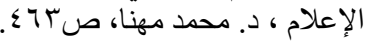

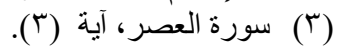

تكوين رأي عام صائب يعي الحقائق الدينية ويدرآها ويتأثر بها في معتقداته، وعبادته، ومعاملاته (r). حصلت البرامج الدينية على نسبة r, 9 \% من النوعية الأولى من برامج القنوات الفضائية، مما يؤكد أهمية التعامل مع تلك القنوات باهتمام في نشر برام

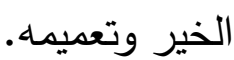

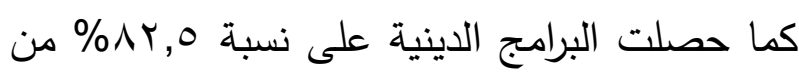
مشاهدي القناة الفضائية المصرية، والبرامج الثقافية ن \% وهي نسب تؤكد مدى أهمية استثمار البث في كل ما ينفع الناس. وخاصة أننا أمة بلاغ لا يصح في حقنا إغفال فرصة ثمينة كهذه لتحقيق الظهور لديننا. ولكن رغم ما سبق تضل القنوات الفضائية تحتاج إلى جهد كبير في جانب الدعوة لنتمكن من مسايرة هذا الكم الهائل من الدعوات المختلفة. وذلك لبيان الحقائق الإسلامية والوصول إلى قلوب الجماهير وعقولها بالحكمة المطلوبة على أن يكون الإعلام هادفاً متصفاً بما يلي: ا-إعلام عصري في مضمونه وأسلوب عرضه، يمزج بين تراث الأمة وبين معطيات العصر ليقدم مادة إعلامية تنطلق من الثوابت بأسلوب مشرق. r-إعلام مهني راقِ يرتكز على خصائص الوسيلة

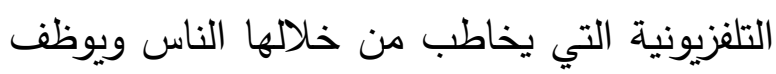
التقنيات الحديثة للوصول إلى الهدف. r-إعلام منفتح فكرياً وحضارياً لأنه ينتمي إلى دين عالمي، وحضارة تفاعلت مع الحضارات الأخرى إلى (Y) (بإِعلام الإسلامي بين الأصالة و المعاصرة، محمد غياث مكتبي ، ص 
- الاهتمام بالجانب الترفيهي الهادف من خلال البرامج المنوّعة. القواعد المنهجية للقنوات الدعوية: ו- التزام الحقائق الموضوعية في اقناع الناس. r- استخدام الشواهد والأدلة والبراهين في تثبيت الحقائق . r- الوضوح واستعمال الأسلوب المشرق والعرض الجيد وتحري الصدق في الأخبار • ع - مراعاة الفائدة في المضدون المنقول.

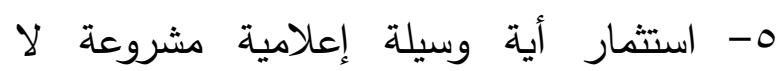
يتناقض أسلوبها مع مضمون رسالة الإعلام الإسلامية، لأنها متميزة عن مضامين الإعلام الأخرى. الإنسان.

7- ترقية اهتمام الناس والسمو بعقولهم ووجدانهم وتتمية الذوق والسلوك نحو الفضائل فهو إعلام للحث على مكارم الأخلاق وفضائل السلوك. - V والعمل على إبراز نقط الالتقاء مع الثقافات الأخرى، من خلال حوارات مع النخبة المثقفة في

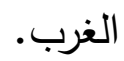

وأهم خطوة في سبيل إنشاء قنوات فضائية دعوية هادفة هي الغاية التي يجب أن تكون أساساً إرضاء الخالق جلت قدرته، قال عز وجل: عَ عَمَا لِاََحَدٍ

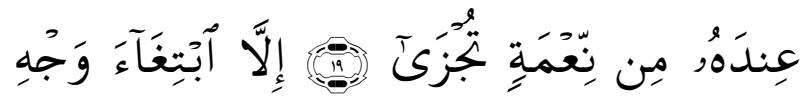

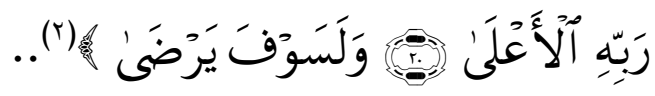

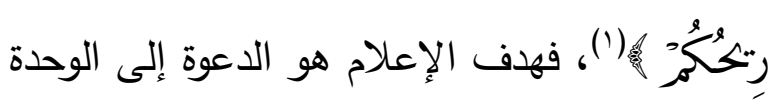
بين المسلمين. - دعم اللغة العربية الفصحى والتمسك بالدعوة إليها، فالفصحى هي لغة القرآن، ومن أسباب فرقتنا عدم محافظتنا على هذه اللغة. - بعث الفكر الإسلامي الأصيل والتماس منابعه في القرآن والسنة، فكل مقومات الحضارة موجودة في الفكر الإسلامي. - بناء الحضارة الإسلامية المعاصرة، ونحن ندعو إلى الماضي ولا نفرط فيه، بل يكون هناك ربط بين

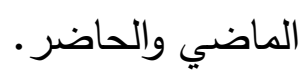
- تجلية محاسن الإسلام ومزاياه وتقريب مفاهيمه وحقائقه حسب قدرات الناس ومداركهم. - بث الفضائل الأخلاقية والسلوك القويم والعادات الإسلامية السليمة، مثل الوصايا بالجار، وردّ الحقوق إلى أهلها، وكفالة اليتيم • الإسله - حماية المجتمع الإسلامي من الأخطار الخارجية والدعايات المسمومة، وذلك بالرد عليها والعمل على نشر المعلومات والأخبار الصادقة. - غرس مبادئ الإسلام والثقافة الإسلامية على مستويات مختلفة أهمها: الأسرة - المدرسة المسجد - وسائل الإعلام المختلفة. - إنشاء المعاهد والكليات الإعلامية المتخصصة الإسـلامية. - الاستيعاب الحق لتقنيات الوسائل الإعلامية الحديثة علماً وممارسة. 
للمسـلمين وجذب المجتمعـات الإسـالامية إلى تقليـد الــمط الغربـي فـي الفكــر والحيــاة والتصــرفات والسلوكيات. (r) (1) (1) - أساس المواجهة لسلبيات البث المباشر هو التربية

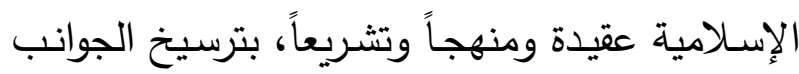
العقدية والإيمانية والثقافة الإسلامية. - الإعلام المعاصر بواقعه الراهن وتثنياته المتطوره وآفاقها البعيدة الواسعة الآفاق. يجعل من الصعب أن ينكمش شعب على نفسه أو ينعزل عن الإعلام دون أن يتـأثر بمـا يُعـرض لـه. (؛) فـالقنوات وسـيلة بـلاغ عصرية يتعيّن استخدامها في الدعوة إلى الله لما لها

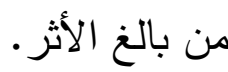

\section{التوصيات}

- يجب أن تتكاثف الجهود الفردية والجماعية في الأسرة والمجتمع لبناء الشخصية الإسلامية ولتربية الجيل المسَلّح بالعقيدة الثابتة والأخلاق الراسخة

$$
\text { وحب الدعوة الإسلامية. }
$$

- على الأسرة والمجتمع وضع رقابة اجتماعية أخلاقية تهدف إلى صيانة المجتمع من الآفات . - التعاون بين القطاع العام والخاص لتمويل محطات تلفزيونية هادفة عامة أو تعليمية أو متخصصة لخدمة المجتمع. - إنشاء مؤسسات إعلامية متخصصة ليكون اهتمامها تهيئة الشباب المسلم الذي أصبح من أهداف الغزو الفكري، وكذلك للفتاة المسلمة وتصحيح

$$
\begin{aligned}
& \text { (1) انظر : الغزو الثقافي للأمسة ماضيه وحاضره، منصور الخريجي، }
\end{aligned}
$$

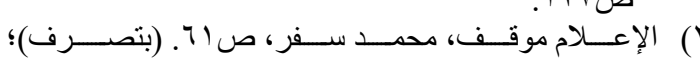

وإن هذه الدعوة لا تؤتي ثمارها حتى يكون لها طرق

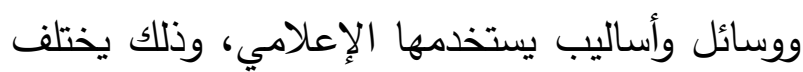
من زمان إلى زمان ويتطور بتطوره فكانت وسائل

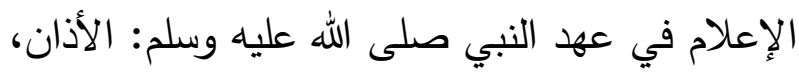

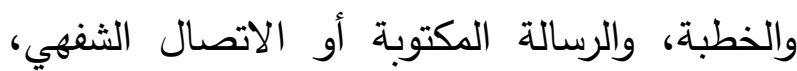
والقدوة الشخصية. (') والإسلام لم يجعل وسائل الدعوة أمراً محدداً بل جاء لئل بالإطار العام لمنهج الدعوة ووسائلها ويقول الله

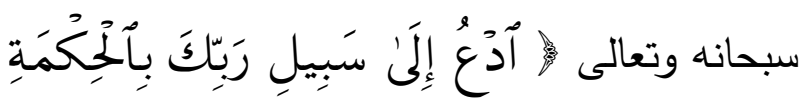

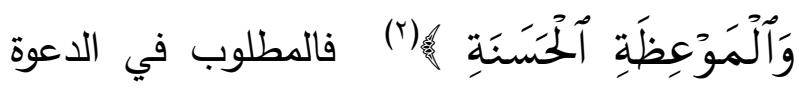
هي الحكمة، ومنها: الحكمة في إختيار واستخدام الوسيلة المناسبة والمتجددة والعصرية للتبليغ.

\section{الخاتمــة}

الحمد لله رب العالمين والصلاة والسلام على أشرف الأنبياء والمرسلين. النتائج

- الإعــلام هـــو الســفير المعبّر عـن الرســالة

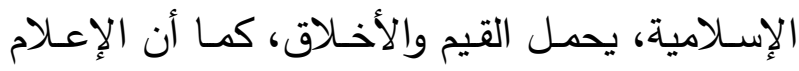
اليوم أمضى الأسلحة في الصراع الحضاري. - القنوات والبث المباشر تمثل خطورة بالغة التأثير على مجتمعاتتا مما يستدعي المواجهة بإبراز صورة صحيحة للمجتمع المسلم. - الإعـلام هـو الناقـل الرئيسـي للثقافـة، وقد كـان

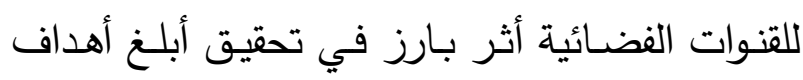
التغريب محاولئً لطمس معالم الهوية الثقافية الذاتية

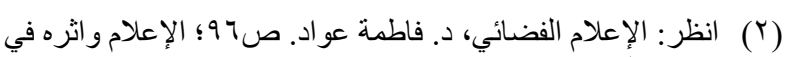

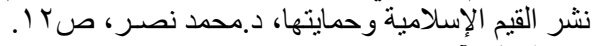

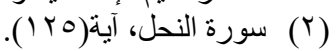




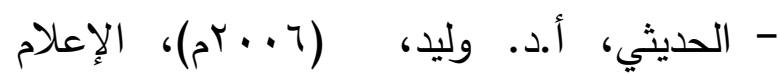
الدولي: : القاهرة، دار الكتب العلمية. - الخريجي، منصور، (ساءـاهـ) الغزو الثقافي للأمة ماضيه وحاضره: طا ـ دار الصميعي. - خليل، عماد الدين، (• (ـ اهـ )، تحليل التاريخ الإسلامي: طا ـ الدوحة ، دار الثقافة. - ذبيان سامي، 9AV ام، الصحافة اليومية

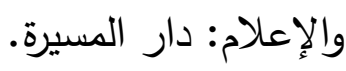
- راضي ، سمير بن جميل، 997 ام، الإعلام الإسلامي رسالة وهدف: رابطة العالم الإسلامي. - الزبيدي، المرتضى، تاج العروس من جواهر

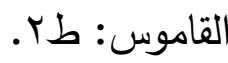

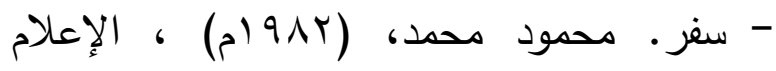
موقف : طا . جدة ، مكتبة تهامة. - الثايع، خالد عبدالرحمن، القنوات الفضائية

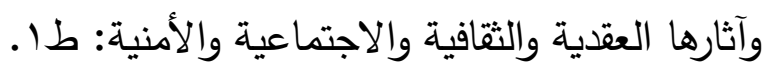
- الثبيلي. عبد الرحمن، (ب99 (م)، نحو إعلام أفضل: طا ـ الرياض. - شرف، عبدالعزيز، . . . بم، المدخل إلى وسائل الإعلام، مصر ، الهيئة المصرية العامة للكتاب.

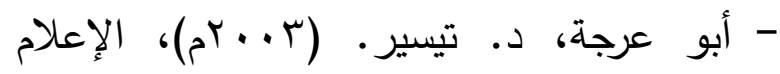
والثقافة العربية: طا ـ عمّان، دار مجدلاوي.

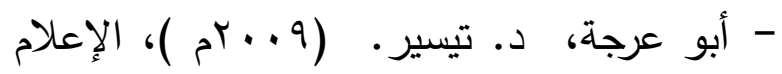
العربي وسائله ورسائله. الأردن، دار مجدلاوي.

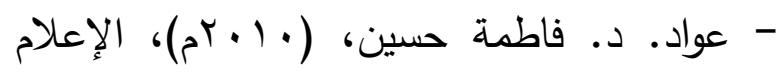
الفضائي: طا ـ الأردن، دار أسامة. - الفيروزآبادي، مجد الدين أبو طاهر محمد بن يعقوب، 0. . ب م، القاموس المحيط، تحقيق: مكتب
الصورة التي يجته أعداء الإسلام بنشرها في الفضائيات. - التسيق والتكامل بين الهيئة الدينية والتربوية ووسائل الإعلام للارتقاء بالذوق في الإعلام من خلال الكلمة الطيبة وعرض القصص القرآني والسيرة النبوية وعرض العقيدة والأخلاق الإسلامية.

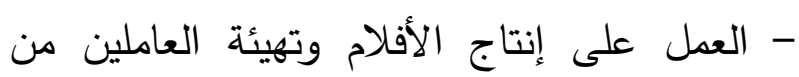

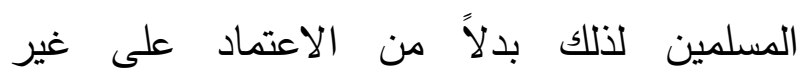
المسلمين، فالأمة الإسلامية اليوم في أشد الحاجة للحفاظ على ثوابتها في الدين والحضارة مع مواكبة

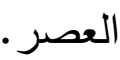
- وضع خطة منظمة متوازنة للبرامج الإعلامية تجمع بين الإعلام والتتقيف والترفيه في إطار من الحفاظ على مبادئ الدين الإسلامي الحنيف. (') - الاستفادة من تقوية البرامج والدروس العلمية والمحاضرات والمباشرة. - أن يُولي الإعلام عناية خاصة للتثقيف النسائي والبرامج الموجهة للمرأة(r)، على الأخص فيما يتعلق بالمحافظة على الأسرة وتربية الطفل والعناية بصحته النفسية والجسدية وتتشئته الصالحة. المصادر والمراجع - امام إبراهيم، 99199، الإعلام والاتصال بالجماهير : طا (، مصر ، مكتبة الأنجلو المصرية.

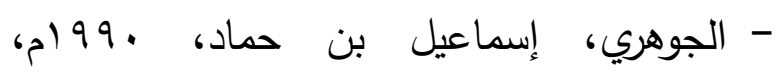
الصحاح تاج اللغة وصحاح العربية: تحقيق: أحمد عبد الغفور عطار، طء، دار العلم للملايين. 
- نصر ، د. محمد إبراهيم، (.91 (م)م، الإعلام

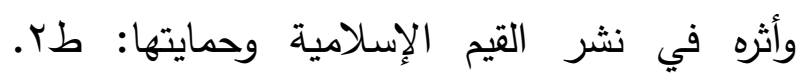
الرياض دار اللواء.

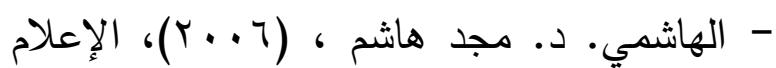

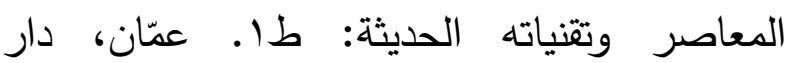

المناهج.

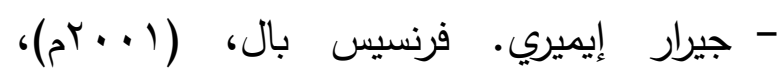

وسائط الإعلام الجديدة: طا. طريزيل ترجمة: فريد

أنطونيوس، بيروت، عويدات للنشر والطباعة.

http://www.doaahonline.net/ http://aqawsat.com/detail -

اللدوريات:

- صحيفة عكاظ، شهر محرم من عام | إك (هـ.

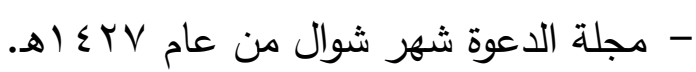

تحقيق التراث في مؤسسة الرسالة، طم، بيروت، مؤسسة الرسالة.

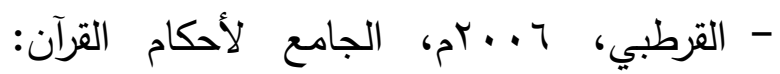

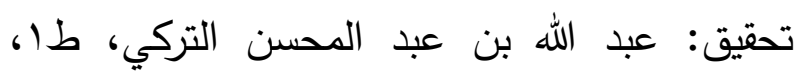

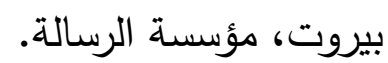
- ابن كثير، 999 ام، تفسير القرآن العظيم،

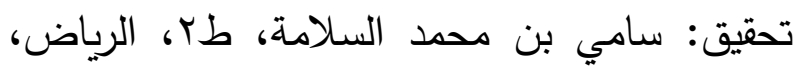
دار طيبة. - مان.

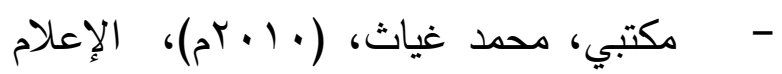

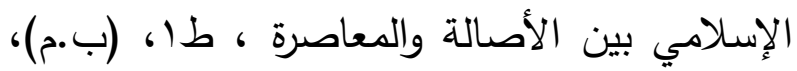

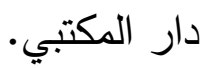

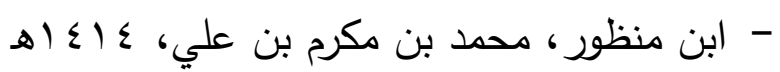
، لسان العرب: طس، بيروت، دار صادر.

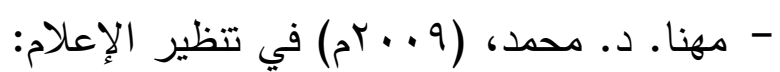

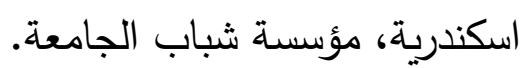




\title{
The Concept of The Purposeful Media And Its Reality in Satellite Channels
}

\author{
Dr. Ayesha bint Mohammed bin Saad Al-Qarni \\ Assistant Professor in Aqeedah and Da'wah \\ - Department of Sharia and Islamic Studies \\ Faculty of Arts and Humanities at \\ King Abdulaziz University in Jeddah
}

\begin{abstract}
Praise be to Allah Alone, Prayers \& Peace be upon who have no Prophet after him, and on his family \& companions.

This research titled "Purposive Media Concept through Reality in Satellite Television Channels" as study of the Media Effect and Modern Proselytizing Impacts of Satellite Television Channels through showing the importance of satellite television channels for Proselytizing field. This research included abstract, two chapters includes five parts.

$1^{\text {st }}$ Chapter: Mass Media

$\circ 1^{\text {st }}$ Part : Media Concept

$\circ 2^{\text {nd }}$ Part: Impacts of International Television

$\circ 3^{\text {rd }}$ Part : Satellite

$2^{\text {nd }}$ Chapter: Proselytizing Impacts

$\circ 1^{\text {st }}$ Part : Impact of Satellite Television Channels

$\circ 2^{\text {nd }}$ Part: Purposive Proselytizing Media

Concluded with research results as: the media is main transporter of cultures, values and ethics, also recommended with importance of keeping on media balance for preparing purposive programs to increase positivity \& invitation to science and knowledge.

Appendixes

I ask Allah for help and devotion ..my success is only by Allah. I trust Him and to Him I go back.
\end{abstract}

